NASA Technical Memorandum 88916

\title{
Finite Element Modeling of Electromagnetic Propagation in Composite Structures
}

Kenneth J. Baumeister

Lewis Research Center

Cleveland, Ohio

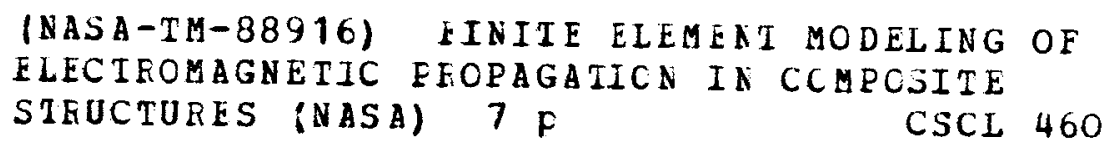

Prepared for the

AP-S International Symposium sponsored by the Institute of Electrical and Electronics Engineers Blacksburg, Virginia, June 15-19, 1987 


\title{
FINITE ELEMENT MOOELING OF ELECTROMAGNEIIC
}

\author{
PROPAGATION IN COMPOSIIE STRUCIURES
}

\author{
Kenneth J. Baumeister \\ National Aeronautics and Space Administration \\ Lewis Research Center \\ Cleveland, Ohio 44135
}

\begin{abstract}
ABSIRACI
A finite element Galerkin formulation has been developed to study electromagnetic propagation in complex two-dimensional absorbing ducts. The reflection and transmission at entrance and exit boundaries are determined by coupling the finite element solutions at the entrance and exit to the eigenfunctions of an infinite uniform perfect conducting duct. Example solutions are presented for electromagnetic propagation with absorbing duct walls and propagation through dielectric-metallic matrix materials.
\end{abstract}

\section{INTRODUCTION}

For inlets and exhaust ducts of jet engines, the structural design and materials are usually determined by aerodynamic, thermodynamic, and structural requirements. In recent military applications; however, electromagnetic constraints have begun to play a major role in determining the structural composition and geometrical configurations of inlet nacelles and exhaust ducts. Clearly, the aerodynamic and electromagnetic disciplines must interact in an effective manner to produce an efficient propul. sion system.

The NASA Lewis grant program in electromagnetics (Refs. I and 2) has been concerned with a basic understanding of electro magnetic propagation in internal propulsion systems. Following the same theme, the present paper presents a finite element analysis potentially capable of evaluating the electromagnetic absorption and scattering properties of jet engines composed of complex structural geometries and composite materials.

\section{METHOD OF ANALYSIS}

The propagation of electromagnetic waves are studied in the two-dimensional $(y, z)$ finite element network shown in Fig. 1. This configuration is ideal for modeling the grazing absorption by wall materials or direct penetration through materials inside the duct. The calculation domain is composed of uniform infi. nitely long entrance and exit regions with perfectly conducting walls and the central, variable property, nonuniform region. 
In the absorbing variable property region of $F i g .1$, the finite element analysis is employed to determine the field var iable. For harmonic wave propagation in variable property mate rials, Maxwell's equations can be combined to yield a wave equation of the form

$$
\nabla \times\left[\begin{array}{lll}
v & \times \bar{H} \\
& \varepsilon
\end{array}\right]=\omega^{2} \mu \bar{H}
$$

where $H$ represents the magnetic field, $\varepsilon$ the complex permittivity, $\mu$ the permeability and $\omega$ the wave frequency. For TM (transverse magnetic) wave propagation in the two dimensional geometry of Fig. 1, Eq. (1) reduces to

$$
\nabla \cdot \frac{1}{\varepsilon} \nabla H_{x}+\omega^{2} \mu H_{x}=0
$$

The boundary conditions associated with Eq. (2) require setting the normal gradient of $H_{x}$ to zero at the perfectly conducting outer walls and matching the finite element solutions at the entrance and exit planes of the nonuniformity to the well. known analytical eigenfunction expansions in the uniform inlet and outlet ducts. This permits a multimodal representation accounting for reflection and transmission at the ducts inlet and outlet.

Equation (2) and the appropriate boundary conditions have been solved by Finite Element Theory using the Method of Weighted Residuals. Details of the solution procedure can be found in Ref. 3.

\section{RESULTS AND COMPARISONS}

For theory and code validation, the finite element solution is first applied to a case where an exact solution exits. Next, the finite element solution will be applied to problems with grazing absorption and normal incidence on composite materials. The results are expressed in terms of nondimensional quaritities. The axial coordinates have been scaled by the duct height, the permittivity and permeability by the free space values and the frequency by the duct height and the speed of light. Also, $j$ represents the square root of 1 .

\section{Example 1 - Reflection and Transmission with Normal Incidence}

The first case considers a step change in dimensionless per mittivity from 1 to 4 at the dimensionless axial position of $z$ equals 0.25 inside the finite element grid. As shown in fig.?, for an incident plane wave of dimensionless rrequency $2 \pi$, the finite element and exact analytical theories are in good agreement for the absolute magnitude of the magnetic intensity $H_{x}$. Ref. erence 3 contains additional validation examples.

\section{Example 2. Grazing Wall Absorption}

Figure 3 shows a configuration with wall absorbers placed at the bottom and top of the duct for materials with a dimensionless 
permeability of 4.1 and permittivity of 1.-j2.83. Again for an incident plane wave of dimensionless frequency $2 \pi$, the absolute magnitude of the magnetic field is displayed in the duct. A five mode expansion in the entrance and exit ducts was sufficient to obtain convergence. As seen in Fig. 3 , the magnetic field has decreased to near zero al the walls but remains relatively high in the center of the duct.

\section{Example 3. Microscopic Absorption and Reflection}

The previous two examples employed the macroscopic properties of $\mu$ and $\varepsilon$. However, many advanced coating material and structures employ small ferrite particles for absorption or slender metallic rods for structural strength. In these cases, aver age values of $\mu$ and $\varepsilon$ are difficult to estimate. However, with the large storage capacity of the modern computer, small test samples of the detailed material structure can now be modeled on the computer. Figure $4(a)$ displays a sample with two small iron squares 0.0005 in. along a side embedded in an epoxy of dimen. sionless $\varepsilon=2.0-j 0.001$ and $\mu=1.0$. For an incident plane wave of $9 \mathrm{GHz}$, the magnetic field lines are shown in Fig. $4(\mathrm{~b})$. In this case, comparison of the input plane wave to the reflected modes at the entrance indicate that 53.3 percent of the incoming energy was reflected back down the duct. Without the iron rods, the reflected energy due to the base material was negligible. This example illustrates how hidden internal metallic structural material can significantly effect reflection coefficients.

\section{CONCIUDING REMARKS}

The finite element method has been developed to handle the problem of electromagnetic propagation in a duct with varying wall properties and geometries. The numerical formulation is rela tively simple to use and appears to give very accurate results. For higher frequencies many wave lengths will exist in the duct requiring a large number of elements. With the expanded memory capability of the modern computer, the restriction does not represent a severe limitation of the method.

\section{REFERENCFS}

1. C.S. Lee, S.L. Chuang, and S.W. Lee, "A Simple Version of Corrugated Waveguide: Smooth Walled Circular Waveguide Coated with Lossy Magnetic Material," AP.S International Symposium Digest, New York: IEEE, 1985, pp. 303-306.

2. H.M. Noh and P.H. Pathak, "A High Frequency Analys is of Electromagnetic Plane Wave Scattering by Perfectly Conducting Semi-infinite Parallel Plate and Rectangular Waveguides with Absorber Coated Inner Walls," NASA CR. 179759, 1986.

3. K.J. Baumeister, "Finite Element Analys is of Electromagnetic Propagation in an Absorbing Wave Guide," NASA 1M-88866, 1986. 


\section{ORIGINAL PACX D \\ of POOR QuAerry}

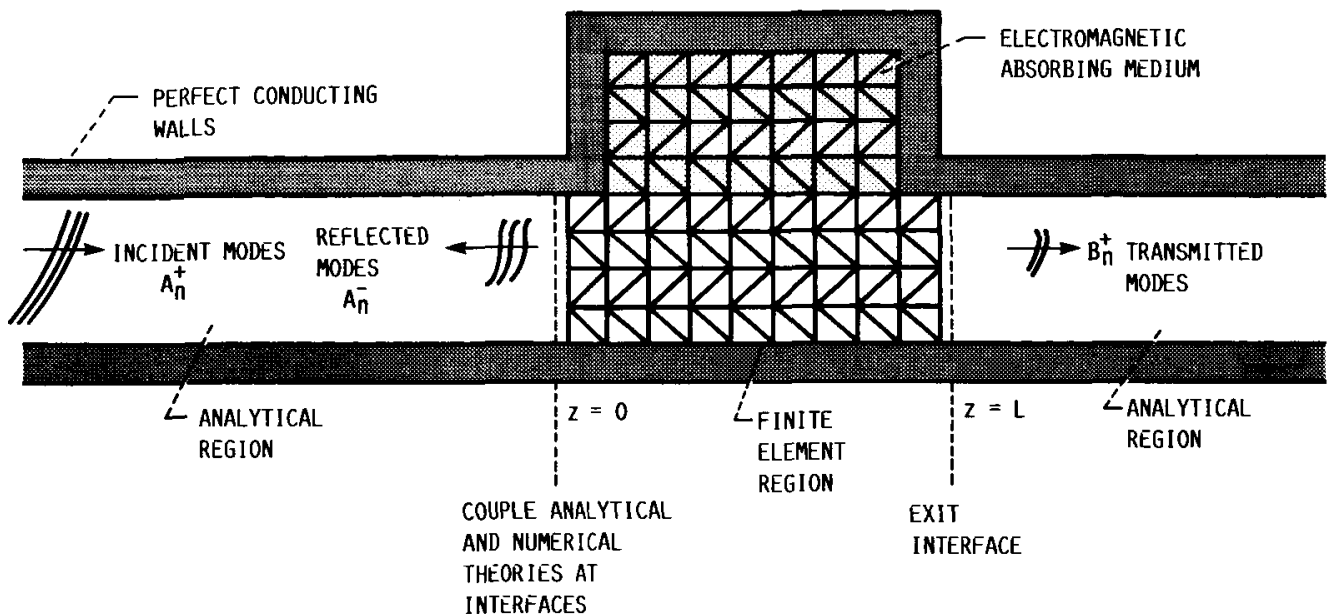

Figure 1.- Two dimensional wave guide finite element model.

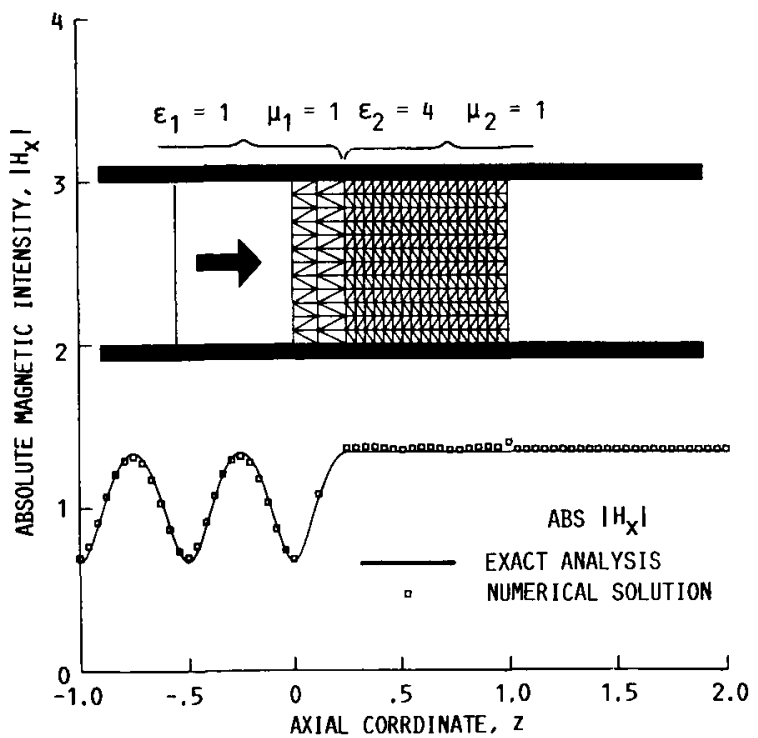

FIGURE 2. - A COMPARISON OF THE MAGNITUDE OF THE AXIAL MAGNETIC INTENSITY VARIATION ALONG THE LOWER WALL IN A UNIFORM DUCT WITH PERFECTLY CONDUCTING WALLS AND A 1.0 AND $\varepsilon_{2}=4.0$ ) AS OBTAINED BY USING AN EXACT SOLUTION AND A FINITE SOLUTION FOR A PLANE WAVE (MODE-ONE) INCIDENT AT $Z=0$ WITH $\omega=2 \pi$. 
ORIGINAL PAGE IS OF POOR QUAUT

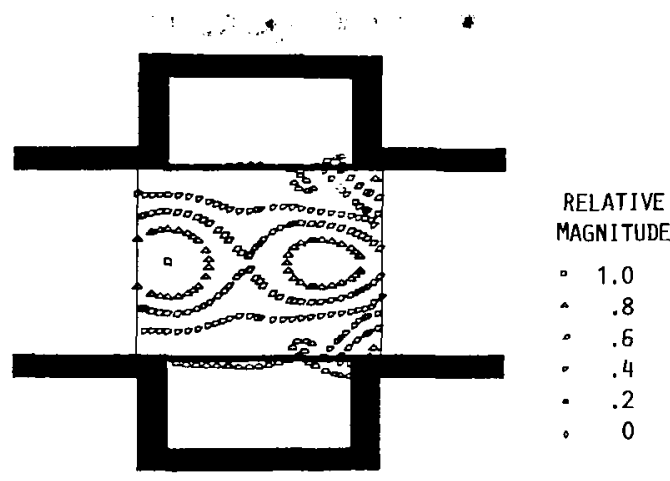

FIgURE 3. - EFFECT OF UPPER AND LOWER WALL ABSORBERS ON THE MAGNITUDE OF THE MAGNETIC FIELD FOR A FIVEMODE MODAL EXPANSION IN THE ENTRANCE AND EXIT DUCTS $(\omega=2 \pi)$.

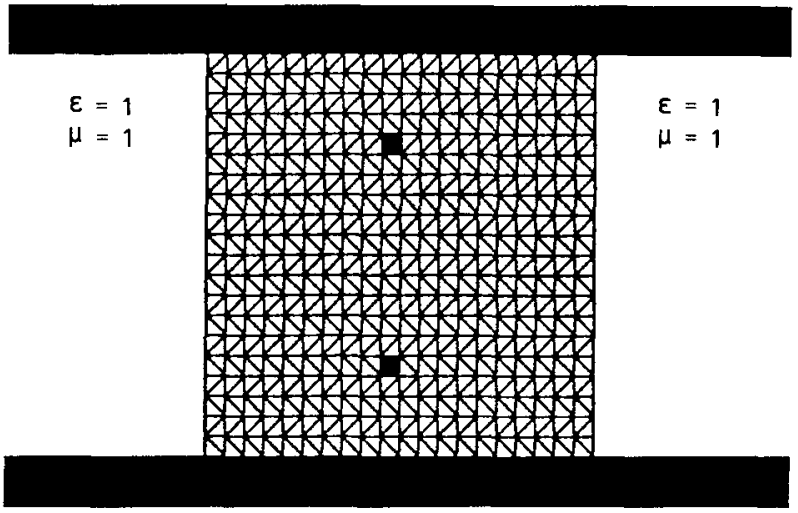

(A) IRON ROD LOCATION.

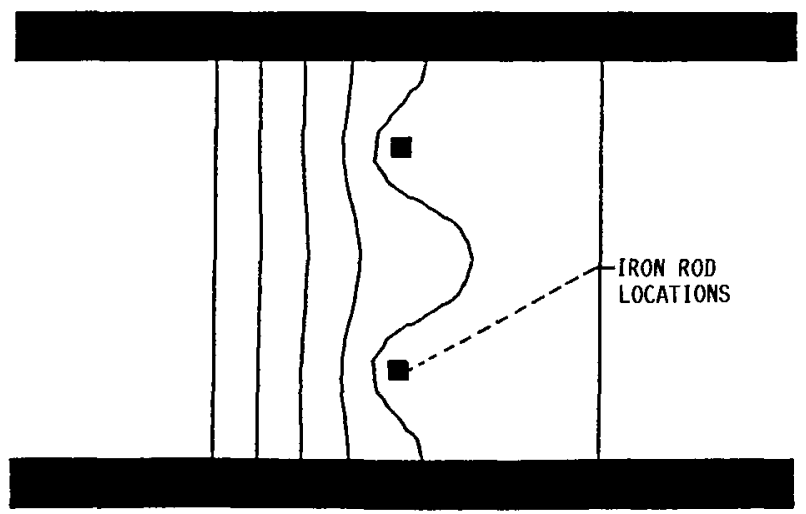

(B) Magnetic Field contours.

Figure 4. - MAGNetic FIELD CONTOURS FOR A PLANE 9 GHz WAVE IMPINGING ON TWO IRON RODS IMBEDDED IN A EPOXY FIELD. SAMPLE SIZE IS ON TWO IRON RODS IMBEDDED 


\begin{tabular}{|c|c|c|}
\hline $\begin{array}{l}\text { 1. Report No. } \\
\text { NASA TM-88916 }\end{array}$ & 3. Recipient's Catalo & 3. Recipient's Catalog No. \\
\hline \multicolumn{2}{|l|}{ 4. Title and Subtitle } & 5. Report Date \\
\hline \multicolumn{2}{|c|}{$\begin{array}{l}\text { Finite Element Modeling of Electromagnetic } \\
\text { Propagation in Composite Structures }\end{array}$} & \begin{tabular}{|l|} 
6. Performing Organization Code \\
$505-62-21$ \\
\end{tabular} \\
\hline \multirow{2}{*}{\multicolumn{2}{|c|}{ Kenneth J. Baumeister }} & $\begin{array}{l}\text { 8. Performing Organization Report No. } \\
\text { E-3341 } \\
\end{array}$ \\
\hline & & 10. Work Unit No. \\
\hline \multirow{2}{*}{\multicolumn{2}{|c|}{$\begin{array}{l}\text { 9. Performing Organization Name and Address } \\
\text { National Aeronautics and Space Administration } \\
\text { Lewis Research Center } \\
\text { Cleveland, Ohio } 44135\end{array}$}} & \multirow{2}{*}{\begin{tabular}{|l|} 
11. Contract or Grant No. \\
13. Type of Report and Period Covered \\
Technical Memorandum
\end{tabular}} \\
\hline & & \\
\hline \multicolumn{2}{|c|}{$\begin{array}{l}\text { 12. Sponsoring Agency Name and Address } \\
\text { National Aeronautics and Space Administration } \\
\text { Washington, D.C. } 20546\end{array}$} & \begin{tabular}{|l|} 
14. Sponsoring Agency Code \\
\end{tabular} \\
\hline \multicolumn{3}{|c|}{$\begin{array}{l}\text { 15. Supplementary Notes } \\
\text { Prepared for the AP-S International Symposium, sponsored by the Institute of } \\
\text { Electrical and Electronics Engineers, Blacksburg, Virginia, June 15-19, } 1987 \text {. }\end{array}$} \\
\hline \multicolumn{3}{|c|}{$\begin{array}{l}\text { A finite element Galerkin formulation has been developed to study electromagnetic } \\
\text { propagation in complex two-dimensional absorbing ducts. The reflection and } \\
\text { transmission at entrance and exit boundaries are determined by coupling the } \\
\text { finite element solutions at the entrance and exit to the eigenfunctions of an } \\
\text { infinite uniform perfect conducting duct. Example solutions are presented for } \\
\text { electromagnetic propagation with absorbing duct walls and propagation through } \\
\text { dielectric-metallic matrix materials. }\end{array}$} \\
\hline \multicolumn{3}{|c|}{$\begin{array}{l}\text { Finite element; Electromagnetic; Wave } \\
\text { guide; Composite structure }\end{array} \quad\left[\begin{array}{l}\text { 18. Distribution Statement } \\
\text { Unclassified - unlimited } \\
\text { STAR Category } 70\end{array}\right.$} \\
\hline $\begin{array}{r}\text { 19. Security Classif. (of this report) } \\
\text { Unc las s if ied }\end{array}$ & page) & 22. Price* \\
\hline
\end{tabular}

*For sale by the National Technical Intormation Service. Springtield. Virginia 22161 